Original research article

\title{
Stent-assisted coiling of very small wide-necked intracranial aneurysms: Complications, anatomical results and clinical outcomes
}

\author{
Wenjun Ji ${ }^{a, 1}$, Huibin Kang ${ }^{a, b, 1}$, Aihua Liu ${ }^{a, *}$, Youxiang Li $^{a, *}$, Xin Feng ${ }^{a}$, \\ Zenghui Qian ${ }^{a}$, Xiaolong Wen ${ }^{a}$, Wenjuan Xu ${ }^{a}$, Chuhan Jiang ${ }^{a}$, \\ Xinjian Yang ${ }^{a}$, Zhongxue $\mathrm{Wu}^{a}$ \\ ${ }^{a}$ Department of Interventional Neuroradiology, Beijing Tiantan Hospital, Beijing Neurosurgical Institute, \\ Capital Medical University, Beijing, China \\ ${ }^{\mathrm{b}}$ Department of Neurosurgery, Beijing Luhe Hospital, Capital Medical University, China
}

\section{A R T I C L E I N F O}

Article history:

Received 12 October 2015

Accepted 19 July 2016

Available online 28 July 2016

Keywords:

Intracranial aneurysm

Stent

Coiling

Very small

Wide-necked

\begin{abstract}
A B S T R A C T
Background and objective: Treatment of very small $(\leq 3 \mathrm{~mm})$ wide-necked intracranial aneurysms remains controversial, we investigated the efficacy and safety of stent-assisted coiling of such aneurysms.

Methods: From September 2008 to December 2012, 112 very small wide-necked intracranial aneurysms in 108 patients were embolized with stent-assisted coiling. We assessed the initial neurological conditions, complications and anatomic results. The follow-up results were evaluated with DSA and mRS.

Results: Stent deployment was successful in 104 of 108 procedures (96.3\%). 11 complications (10.2\%) occurred during procedures, including 5 events of aneurysm rupture, 3 events of thromboembolism. The rate of complication, rupture and thromboembolism was not statistically different between the ruptured and unruptured patients $(P=0.452$, $P=0.369, P=1.000$, respectively). The initial aneurysmal occlusion was Raymond scale (RS) 1 in 34 patients (31.5\%), RS2 in 53 patients (49.1\%), and RS3 in 21 patients (19.4\%). 79 aneurysms were available for anatomic follow-up of 12-47 months, stable occlusion in 45 aneurysms (57.0\%), progressive complete occlusion in 34 aneurysms $(43.0 \%) .95$ patients (88.0\%) were available for a clinical follow-up of 12-52 months, 92 patients (96.8\%) had favorable clinical outcomes ( $\mathrm{mRS} \leq 2), 3$ patients $(3.2 \%)$ had morbidity (mRS: $3-5)$. The morbidity was not statistically different between the ruptured and unruptured patients $(P=1.000)$.
\end{abstract}

\footnotetext{
* Corresponding authors at: Department of Interventional Neuroradiology, Beijing Tiantan Hospital, Beijing Neurosurgical Institute, Capital Medical University, Tiantan Xili 6, Dongcheng District, Beijing 10050, China. Tel.: +86 10 67098852; fax: +86 1065113164.

E-mail addresses: jwjdoctor@sina.com (W. Ji), kanghuibindoctor@163.com (H. Kang), liuaihuadoctor@163.com (A. Liu), liyouxiang_ttyy@126.com (Y. Li), 627440730@qq.com (X. Feng), 370453167@qq.com (Z. Qian), 371357547@qq.com (X.Wen), 841700194@qq.com (W. Xu), jiangchuhan_ttyy@126.com (C. Jiang), 1053157367@qq.com (X. Yang), wuzhongxue_yjs@126.com (Z. Wu).

${ }^{1}$ Wenjun Ji and Huibin Kang contributed equally to this work. http://dx.doi.org/10.1016/j.pjnns.2016.07.004 0028-3843/@ 2016 Polish Neurological Society. Published by Elsevier Sp. z o.o. All rights reserved.
} 
Conclusions: Stent-assisted coiling of very small wide-necked intracranial aneurysms may be effective and safe. Because of low risk of rupture in such aneurysms, the coiling of unruptured such aneurysms must be selective. The long-term efficacy and safety of coiling such aneurysms remains to be determined in larger prospective series.

(C) 2016 Polish Neurological Society. Published by Elsevier Sp. z o.o. All rights reserved.

\section{Introduction}

The International Subarachnoid Aneurysm Trial (ISAT) provided evidence of the efficacy of coiling [1]. Endovascular coiling of intracranial aneurysms has become an efficient technique comparable to surgical clipping. However, International Subarachnoid Aneurysm Trial hasn't specifically provided the outcomes of endovascular treatment of very small ( $\leq 3 \mathrm{~mm}$ ) intracranial aneurysms. To the best of our knowledge, endovascular treatment for very small intracranial aneurysms has been sporadically reported and Guglielmi detachable coiling of very small intracranial aneurysms was demonstrated to be feasible. However, this technique remains controversial for its high failure rates, especially for wide-necked and very small aneurysms, which are considered to have technically challenging and high complication rates $[2,3]$.

Brinjikji et al. reported the results of a meta-analysis suggesting that the treatment of very small aneurysms was feasible and effective in more than $90 \%$ of treated aneurysms [4]. However, that study did not clearly show the results of very small intracranial aneurysms with wide-necked. In the present study, to investigate the feasibility and efficacy of stent-assisted coiling of very small aneurysms with a maximum aneurysm size $\leq 3 \mathrm{~mm}$ and a dome-to-neck ratio $<1.5$, we reported our series of 108 patients with initial and mid-long term results of the management of very small wide-necked intracranial aneurysms using stent-assisted coiling.

\section{Materials and methods}

\subsection{Patients}

After institutional review board approval, we performed a retrospective analysis of all consecutive adult patients who underwent attempted stent-assisted coiling of intracranial aneurysms at our institution between September 2008 and December 2012 to identify embolization procedures performed in very small (maximum dimension, $3 \mathrm{~mm}$ ) and wide-necked (dome-to-neck ratio $<1.5$ ) intracranial aneurysms. The indication for treatment and its modality were based on characteristics of individual patients and aneurysms through interdisciplinary decision making by a neurovascular team, offering endovascular embolization as a primary treatment. For ruptured very small aneurysms, the patients with older age, and the aneurysms located in the posterior circulation were included. For very small unruptured intracranial aneurysms, patients included for treatment were according to results of International Study of Unruptured Intracranial Aneurysms (ISUIA) and Unruptured Cerebral Aneurysm Study (UCAS) of Japan [5-7]. Aneurysms with irregular shape, located in anterior communicating artery and posterior communicating artery, aneurysm size increasing after dynamic imaging follow-up, and multiple aneurysms with previous subarachnoid hemorrhage were included. Furthermore, patient preferences were also considered.

All patients provided approval for the use of their medical records for retrospective analysis. Patients were identified through a search of angiographic records and then further identified on the basis of the size of their intracranial aneurysms. For each patient, demographic data, clinical presentation, clinical outcome, aneurysm size and dome-toneck ratio measured by 3D digital subtraction angiography (DSA), aneurysm rupture status, and aneurysm location were collected. For patients who presented with subarachnoid hemorrhage, Hunt and Hess scores were provided by the neurology team who was responsible for the management of the patients.

\subsection{Endovascular procedure and complications}

Patients with unruptured aneurysms or ruptured aneurysms in the nonacute phase were premedicated for 3 days prior to the procedure with dual antiplatelet therapy consisting of aspirin $(100 \mathrm{mg} / \mathrm{d})$ and clopidogrel $(75 \mathrm{mg} / \mathrm{d})$. Patients with acutely ruptured aneurysms were loaded with clopidogrel (300 mg) and aspirin (300 mg) before the procedure.

Patients typically were treated while under general anesthesia. Typically, 6F or 8F guiding catheters (Envoy, Codman, Miami Lakes, FL, USA) were placed into the internal carotid or vertebral arteries. All of the DSA examinations were performed by using a biplane, digital angiography suite (Integris Philips Medical Systems, Best, Netherlands). A volume of 24(18) $\mathrm{ml}$ of nonionic contrast medium was injected through a 6-8 F catheter by use of an injector with a velocity of 4(3) $\mathrm{ml} / \mathrm{s}$. Biplane DSA images of the entire circulation were usually performed, followed by "working-projection" DSA.A coaxial technique was used for microcatheter and stent catheter access. We navigated the microcatheter (Prowler select plus, Codman, Fremont, CA, USA; Renegade microcatheter, Stryker Neurovascular Freemont, CA, USA; Headway21, eV3, Irvine, CA, USA) over a standard microguidewire (Traxcess14, Microvention, Aliso Viejo, CA, USA; Synchro14, Boston Scientific, Fremont, CA, USA) as distally as possible beyond the aneurysm neck. Another steam-shaped microcatheter (Prowler-14, Cordis Neurovascular, Bridgewater, NJ, USA) or Echelon-10 (eV3, Irvine, CA, USA) was navigated into the aneurysm dome or near the neck. Positioning of the microcatheters, a coil was partially deployed into the aneurysm sac, and then the stent and delivery system were advanced beyond the neck within the microcatheter. The stent was semi-deployed or fully deployed, Aneurysms were coiled until there was no further evidence of angiographic contrast 
filling of the aneurysm or until the microcatheter was pushed out by the coil mass. After the completion of embolization, and all stents were fully deployed. Of 112 aneurysms, 108 stents were used (Leo stent, Balt, Montmorency, France; Solitaire stent, eV3, Irvine, CA, USA; Enterprise stent, Codman Neurovascular, Miami Lakes, FL, USA; Neuroform stent, Boston Scientific/Target Therapeutics, Freemont, CA, USA). We used bare platinum coils for most of the patients in this series including the Orbit Detachable Coil System (Cordis Neurovascular, Miami Lakes, FL, USA), Gugleilmi detachable coils (Boston Scientific, Fremont, CA, USA), Microplex (Microvention, Aliso Viejo, CA, USA). Axium 3D and Helix (eV3, Irvine, CA, USA) or a combination of them. In 112 aneurysms, 1 coil was used in 75 patients, 2 coils were used in 25 patients, and 3 coils were used in 12 patients.

After the procedure, clopidogrel $(75 \mathrm{mg} / \mathrm{d})$ was given orally for 6 weeks and aspirin $(100 \mathrm{mg} / \mathrm{d})$ was given for 6 months. Periprocedural adverse events such as aneurysm rupture, thromboembolism were recorded.

\subsection{Anatomic results and clinical follow-up}

Patients who survived the hospital stay were routinely scheduled for a follow-up visit at 6 months, 1year, and 3years for follow-up with DSA. The anatomic results were evaluated with the Raymond grading system as follows: complete occlusion (Raymond Scale 1, RS1), residual neck (Raymond Scale 2, RS2) and residual aneurysm (Raymond Scale 3, RS3) [8]. Anatomic results of follow-up were classified as stable (no interval change of occlusion degree compared with the initial result), progressive complete occlusion (initially residual neck or residual aneurysm), and recurrence. Each patient's clinical status was evaluated at last follow-up using the modified Rankin Scale (mRS).

\subsection{Statistical analysis}

Mean and frequency data were compared using student $t$ test and the $\chi^{2}$ test or fisher exact test, respectively. All data were statistically analyzed using SPSS16.0 statistical package (SPSS for windows, release 9.13.2007, SPSS Inc.). The significance threshold was established at $P<0.05$.

\section{Results}

\subsection{Patient and aneurysm characteristics}

A total of 112 very small wide-necked intracranial aneurysms in 108 patients (41 male, 67 female) were embolized with

\section{Table 1 - Baseline characteristics of the patients.}

\begin{tabular}{ll} 
Characteristics & Patients $(n, \%)$ \\
\hline Age & \\
Mean \pm SD & $53.9 \pm 7.4$ \\
Range & $31-72$ \\
Gender & \\
Male & $41 / 108(38.0 \%)$ \\
Female & $67 / 108(62.0)$ \\
Smoking & $45 / 108(41.7 \%)$ \\
Current smoker & $42 / 45(93.3 \%)$ \\
Former smoker & $3 / 45(6.7 \%)$ \\
Medical history & \\
Hypertension & $70 / 108(64.8 \%)$ \\
Treatment of hypertension & $26 / 70(37.1 \%)$ \\
No. of multiple aneurysms patients & $4 / 112(3.6 \%)$ \\
Ruptured aneurysm patients & $56 / 108(51.9 \%)$ \\
Hunt and Hess I-II & $43 / 56(76.8 \%)$ \\
Hunt and Hess III & $12 / 56(21.4 \%)$ \\
Hunt and Hess IV & $1 / 56(1.8 \%)$ \\
Unruptured aneurysm patients detection & $52 / 108(48.1 \%)$ \\
Screening & $12 / 52(23.1 \%)$ \\
Headache or dizziness & $30 / 52(57.7 \%)$ \\
Symptoms caused by embolic episodes & $8 / 52(15.4 \%)$ \\
Others & $2 / 52(3.8 \%)$ \\
mRS (0-2) & $52 / 52(100 \%)$ \\
\hline
\end{tabular}

stent-assisted coiling; the patients were 31-72 years of age (mean, 53.9 years). Of 112 aneurysms, 58 (51.8\%) were ruptured and $54(48.2 \%)$ were unruptured. The locations of the 112 aneurysms included: ICA-ophthalmic $(n=58)$, posterior communicating artery $(n=27)$, anterior communicating artery $(n=6)$, ICA-cavernous $(n=5)$, middle cerebral artery $(n=3)$, basilar tip $(n=3)$, ICA-carotid terminus $(n=3)$, and posterior cerebral artery $(n=3)$, anterior cerebral artery $(n=2)$, and vertebral artery $(n=2)$. The aneurysm size was $2.62 \pm 0.29 \mathrm{~mm}$ (range, 1.8-3.0 mm) in maximum dome diameter, while the dome-to-neck ratio was $1.03 \pm 0.24$ (range, 0.5-1.4). Tables 1 and 3 show the characteristics of the patients and aneurysms. The characteristics of the patients and aneurysms were not statistically different between the ruptured group and unruptured group (Tables 2 and 4).

\subsection{Procedural feasibility and complication}

Stent was successfully deployed in 104 of 108 patients (96.3\%). In 4 patients (3.7\%), failure to deploy the stent was due to the inability to cross the aneurysmal neck with the microcatheter (2 patients) and vessel vasospasm (2 patients).

In the 108 patients, 11 adverse events occurred during the procedure.7 occurred in ruptured aneurysm, 4 occurred in unruptured aneurysm. The rate of procedure-related

Table 2 - Patient characteristics in unruptured and ruptured aneurysms.

\begin{tabular}{lccc} 
Characteristics & Ruptured aneurysm & Unruptured aneurysm & P-Value \\
\hline Age (mean \pm SD) & $54.8 \pm 8.5$ & $52.9 \pm 5.8$ & $0.191(F=7.782)$ \\
Gender (female/male) & $34 / 22$ & $31 / 21$ & $0.907\left(\chi^{2}=0.014\right)$ \\
Smoking & $25 / 56$ & $20 / 52$ & $0.724\left(\chi^{2}=0.175\right)$ \\
Hypertension & $39 / 56$ & $31 / 52$ & $0.614\left(\chi^{2}=0.255\right)$ \\
\hline SD: standard deviation. & & & \\
\hline
\end{tabular}


Table 3 - Baseline characteristics of the aneurysms.

\begin{tabular}{lc} 
Characteristics & Aneurysms (n, \%) \\
\hline Ruptured aneurysms & $58 / 112(51.8 \%)$ \\
Unruptured aneurysms & $54 / 112(48.2 \%)$ \\
Aneurysm maximum diameter & $2.62 \pm 0.29 \mathrm{~mm}$ \\
Dome-to-neck ratio & $1.03 \pm 0.24$ \\
Anterior circulation & $104 / 112(92.9 \%)$ \\
ICA-Ophthalmic & $58 / 112(51.8 \%)$ \\
ICA-Posterior communicating & $27 / 112(24.1 \%)$ \\
ICA-Cavernous & $5 / 112(4.5 \%)$ \\
ICA-Carotid terminus & $3 / 112(2.7 \%)$ \\
Anterior communicating artery & $6 / 112(5.4 \%)$ \\
Middle cerebral artery & $3 / 112(2.7 \%)$ \\
Anterior cerebral artery & $2 / 112(1.7 \%)$ \\
Posterior circulation & $8 / 112(7.1 \%)$ \\
Basilar tip & $3 / 112(2.7 \%)$ \\
Posterior cerebral artery & $3 / 112(2.7 \%)$ \\
Vertebral artery & $2 / 112(1.7 \%)$ \\
\hline ICA: internal carotid artery. &
\end{tabular}

complication was not statistically different between ruptured and unruptured aneurysm $(P=0.452) .5$ procedural-related ruptures $(4.6 \%)$ occurred during the procedure, three of them were aneurysmal dome perforations by a microguidewire, while the other two were caused by the retrieval of a coil that migrated through the stent struts to the distal portion of the middle cerebral artery. Intraprocedural aneurysm rupture occurred more frequently in the ruptured aneurysm than it occurred in unruptured aneurysm (7.1\% vs. $1.9 \%)$, but the rate of intraprocedural aneurysm rupture was not statistically different $(P=0.369)$. Three events of thromboembolisms occurred during the procedure, the rate of thromboembolism was not statistically different between the ruptured and unruptured aneurysm $(P=1.000)$. Complications including hemorrhagic and ischemic events among different stent types were not statistically significant $(P=0.352 ; P=0.118)$. The summary of the feasibility and complication listed in Table 5.

\section{Table 4 - Aneurysm characteristics in unruptured and ruptured aneurysms.}

\begin{tabular}{lccc} 
Characteristics & Ruptured aneurysm & Unruptured aneurysm & $P$-Value \\
\hline Aneurysm maximum diameter (mean \pm SD) & $2.55 \pm 0.31$ & $2.68 \pm 0.27$ & $0.586(F=0.298)$ \\
Dome-to-neck ratio (mean \pm SD) & $1.05 \pm 0.26$ & $1.00 \pm 0.21$ & $0.073(F=3.270)$ \\
Anterior/posterior circulation & $52 / 6$ & $52 / 2$ & $0.173\left(\chi^{2}=1.860\right)$ \\
\hline
\end{tabular}

Table 5 - Summary of periprocedural outcome of coiling.

\begin{tabular}{|c|c|c|}
\hline Characteristics & $n(\%)$ & P-Value \\
\hline \multicolumn{3}{|l|}{ Feasibility } \\
\hline Success & $104 / 108(96.3 \%)$ & \\
\hline Ruptured patients & $54 / 56(96.4 \%)$ & $0.992\left(x^{2}=0.000\right)$ \\
\hline Unruptured patients & $50 / 52$ (96.2\%) & \\
\hline Failure & $4 / 108(3.7 \%)$ & \\
\hline Ruptured patients & $2 / 56(3.4 \%)$ & $1.000^{\mathrm{a}}$ \\
\hline Unruptured patients & $2 / 52(3.8 \%)$ & \\
\hline \multicolumn{3}{|l|}{ Anatomic outcome } \\
\hline RS1 & $34 / 108(31.5 \%)$ & \\
\hline RS2 & $53 / 108(49.1 \%)$ & \\
\hline RS3 & $21 / 108$ (19.4\%) & \\
\hline \multicolumn{3}{|l|}{$(\mathrm{RS} 1+\mathrm{RS} 2) / \mathrm{RS} 3$} \\
\hline Ruptured patients & $52 / 4$ & $0.001\left(x^{2}=11.237\right)$ \\
\hline Unruptured patients & $35 / 17$ & \\
\hline Procedure-related complications & $11 / 108(10.2 \%)$ & \\
\hline Ruptured aneurysm & $7 / 56(12.5 \%)$ & $0.452\left(x^{2}=0.564\right)$ \\
\hline Unruptured aneurysm & $4 / 52(7.7 \%)$ & \\
\hline Intraprocedural aneurysm rupture & $5 / 108(4.6 \%)$ & \\
\hline Ruptured aneurysm & $4 / 56(7.1 \%)$ & $0.369^{a}$ \\
\hline Unruptured aneurysm & $1 / 52(1.9 \%)$ & \\
\hline Ischemic events & $3 / 108(2.8 \%)$ & \\
\hline Ruptured aneurysms & $2 / 56(3.6 \%)$ & $1.000^{\mathrm{a}}$ \\
\hline Unruptured aneurysms & $1 / 52(1.9 \%)$ & \\
\hline Puncture site hematoma & $2 / 108(1.8 \%)$ & \\
\hline Others & $1 / 108(0.9 \%)$ & \\
\hline \multicolumn{3}{|l|}{ Complications based on stent types } \\
\hline Neuroform & $3 / 18(16.7 \%)$ & $0.352^{\mathrm{a}}$ \\
\hline Enterprise & $2 / 42(8.3 \%)$ & \\
\hline Solitaire & $2 / 38(5.3 \%)$ & \\
\hline Leo & $1 / 10(10.0 \%)$ & \\
\hline \multicolumn{3}{|l|}{ Complications based on stent types } \\
\hline Open cell & $3 / 18(16.7 \%)$ & $0.118\left(x^{2}=2.448\right)$ \\
\hline Closed cell & $5 / 90(5.6 \%)$ & \\
\hline
\end{tabular}


Table 6 - Anatomic results of follow-up according to initial occlusion.

\begin{tabular}{lcccc} 
Follow-up results & \multicolumn{3}{c}{ Initial occlusion } & No. of \\
\cline { 2 - 4 } & RS1 & RS2 & RS3 & aneurysms (\%) \\
\hline Stable occlusion & 16 & 24 & 5 & $45(57.0 \%)$ \\
Progressive occlusion & & 20 & 14 & $34(43.0 \%)$ \\
\hline RS1: complete occlusion; RS2: residual neck; RS3: residual aneur- \\
ysm.
\end{tabular}

\subsection{Initial anatomic results and results of follow-up}

Initial aneurysm occlusion after coiling was RS1 in 34 patients (31.5\%), RS2 in 53 patients (49.1\%), and RS3 in 21 patients (19.4\%). The rate of occlusion (RS1 + RS2) was statistically different between the ruptured group and unruptured group $(P=0.001)$.

Of 108 aneurysms, 79 (73.1\%) in 76 patients were available for 12-month or longer imaging follow-up with DSA. In 28 patients with 29 aneurysms, no follow-up imaging was performed for the following reasons: follow-up refusal due to old age, financial issues, or other medical conditions (9 patients); follow-up lost (9 patients); and scheduling of a follow-up imaging study (10 patients). The mean follow-up duration was 18.9 months (range, 12-47 months). Overall, imaging follow-up revealed stable occlusion in 45 aneurysms (57.0\%; 16 with RS1, 24 with RS2, and 5 with RS3 at the time of initial coiling) and progressive complete occlusion in 34 (43.0\%; 20 with RS2 and 14 with RS3 at the time of initial coiling). There were no patients of aneurysmal recurrence or in-stent stenosis found during the follow-up. Initial anatomic results and results of follow-up are compared in Tables 5 and 6 .

\subsection{Clinical outcomes of follow-up}

Of 108 patients, 95 patients were available for a clinical followup of 13-52 months (mean, 25.8 months), 92 patients (96.8\%) had favorable clinical outcomes ( $\mathrm{mRS} \leq 2)$. Three patients (2.1\%) had morbidity (mRS: 3-5), no aneurysms ruptured or ruptured during the follow-up, and 13 patients were lost to follow-up and could not be located. Table 7 shows the outcome of follow-up. Rates of current smoking and treatment of hypertension before and after coiling were statistically different $(P=0.001, P=0.018)$. The clinical outcomes were not statistically different between ruptured aneurysms and unruptured aneurysms for favorable outcome and morbidity $(P=0.946, P=1.000)$.

\section{Discussion}

Endovascular coiling for the treatment of intracranial aneurysms has become a widely accepted procedure [4]. However, coiling of wide-necked and very small aneurysms $(\leq 3 \mathrm{~mm}$ in maximum diameter and a dome-to-neck ratio $<1.5$ ) has been considered controversial due to technical difficulties such as the dropping out of microcatheters during coil packing and the high rate of procedural aneurysm rupture [9]. For these reasons, patients with very small intracranial aneurysms were not included in the International Subarachnoid Aneurysm Trial [1]. However, with newly developed coils with better designs and smaller sizes, coiling of very small intracranial aneurysms is far safer than previously. Recent reports have shown that coiling may be an effective strategy for very small intracranial aneurysms $[10,11]$. In addition, stent-assisted aneurysm coiling is well established for wide-necked intracranial aneurysms, because the stent serves as a scaffold to bridge the aneurysm neck and prevent coils from protruding into the parent artery [12].

In our series, stent was successfully deployed in 104 of 108 patients $(96.3 \%)$, stent deployment failed in $3.7 \%$ of patients. The results of two other studies were similar to ours [13-15]. Procedural rupture, one of the most significant complications of coiling, may be caused by perforation with the microguidewire or microcatheter, or may occur during coil placement. The clinical consequences of the rupture range from minimal to massive subarachnoid hemorrhage [16,17], resulting in permanent morbidity in $1.4 \%$ of patients and mortality in $2.4 \%$ [4]. Several earlier reports stated that the risk of intraprocedural aneurysm rupture is higher if the aneurysm is $<3 \mathrm{~mm}$ in maximum diameter. Jun $\mathrm{L}$ et al. reported an intraprocedural rupture rate of 3.8\% [14]. Van Rooij et al. and Nguyen et al. reported that the intraprocedural rupture rate of very small aneurysms was more than twice $(7.7 \%)$ and five times $(11.7 \%)$ that of the rate of larger aneurysms, respectively $[17,18]$. In our series, intraprocedural rupture occurred in 5 aneurysms (4.6\%), and 2 had persistent neurologic morbidity (2.1\%). Several study shown that intraprocedural rupture rates were higher in smaller and ruptured aneurysm when

Table 7 - Clinical outcome of follow-up.

\begin{tabular}{lccc} 
Characteristic & Patients $(N=95)$ before coiling & Patients $(N=95)$ on follow up & P-value \\
\hline Current smoker/smoker & $35 / 40$ & $1 / 40$ & $0.000\left(\chi^{2}=24.227\right)$ \\
Treatment of hypertension/hypertension & $34 / 65$ & $65 / 65$ & $0.018\left(\chi^{2}=5.613\right)$ \\
mRS & & & \\
0-2 & & $92 / 95(96.8 \%)$ & $0.946\left(\chi^{2}=0.005\right)$ \\
$\quad$ Ruptured patients & $47 / 49(95.9 \%)$ & $1.000^{\mathrm{a}}$ \\
$\quad$ Unruptured patients & $45 / 46(97.8 \%)$ & $3 / 95(3.2 \%)$ \\
$3-5$ & $2 / 49(4.1 \%)$ & $1 / 46(2.2 \%)$ \\
$\quad$ Ruptured patients & & \\
$\quad$ Unruptured patients & & \\
\hline${ }^{a}$ Fisher exact test. & &
\end{tabular}


compared with larger and unruptured aneurysms, the result is similar to us (7.1\% vs. $1.9 \%$ ), but our study shown no statistical difference between the ruptured group and the unruptured group, the reason may be the number of patients in this series being small. The rate of thromboembolic events in very small wide-necked aneurysm has not been evaluated thoroughly. Thromboembolic events occurred in 3.1\% in the Ioanniaid et al. series [19]. The morbidity rate due to thromboembolic events was $1.3 \%$ in unruptured aneurysms and $2.1 \%$ in ruptured aneurysms in a meta-analysis [4]. In our series, the rate of thromboembolic events occurred in $2.8 \%$ of aneurysms, there was not statistical different between the ruptured and unruptured aneurysms (3.6\% vs. $1.9 \%)$.

Although 74 (68.5\%) aneurysms in our series were residual neck or residual aneurysm at the time of the initial coiling, no aneurysmal recurrence was seen during the angiographic follow-up. Meanwhile, 34 (43\%) residual neck or residual aneurysms progressed to complete occlusion. Weber et al. were the first to report the progressive occlusion rate of 31 unruptured wide-necked aneurysms using Enterprise stentassisted coiling [12]. They reported that the progressive occlusion was achieved in 10 of 25 patients (40\%) with initial incomplete occlusion aneurysms, and the complete occlusion was achieved in 16 of 31 patients (51.6\%) at the time of followup. Therefore, the initial complete occlusion rate $(19.4 \%, 6$ of $31)$, the progressive occlusion rate $(40 \%)$ and the follow-up complete occlusion rate (51.6\%) were lower than in our series (31.5\%, 43.0\% and 63.0\%) with a mean 18.9-month follow-up. Based on its features, a very small aneurysm is usually embolized using only one or two coils. However, this makes the operators worry about recanalization of the aneurysm. Several previous published reports and our study showed that incomplete initial packing of very small aneurysms did not lead to a high recanalization rate in mid-long term follow-up; Furthermore, some patients become progressively more occluded with further thrombosis on angiographic followup. The high rate of progressive occlusion may be explained by the mechanical and physiological properties of the stent itself. The stent may also promote progressive thrombosis and offer scaffolding for reconstruction of the intimal layer of the parent artery at the aneurysm neck with respect to the mechanical, hemodynamic, and biological benefits provided by stent. These benefits can prevent coil protrusion into the parent artery, reduce flow redirection, reduce intra-aneurysmal blood flow, and promote vessel wall healing $[20,21]$.

Goddard et al. reported four recurrences from 25 small aneurysms coiled with one coil [8]. There was no relationship between the coil embolization ratio and recurrence in that study. Gupta et al. also reported that the embolization of very small aneurysms with one or two coils resulted in thrombosis of the aneurysm despite initial loose packing [22]. Similarly, Yang et al. used undersized coil packing with a loose coil core for very small ruptured aneurysms in 12 patients, only one recurrence was noted [23]. Chalouhi et al. reported that, with the use of stent-assisted coiling, moderate and high aneurysm packing seems to provide equivalent angiographic obliteration rates [24]. In our series, There were no patients of aneurysmal recurrence and rupture, the first reason may be due to high rate $(80.6 \%)$ of moderate and high packing (residual neck and complete occlusion in immediate angiography) with stent-assisted coiling, especial for ruptured aneurysms (52/ $56,92.9 \%)$. The second reason may be due to control of smoking and hypertension which related to growth and rupture of aneurysms $[25,26]$. The third reason may be due to low risk of rupture of the very small aneurysm. The results also need long-term follow-up.

In our series, morbidity on follow-up was $3.2 \%$, mortality was $0 \%$. The morbidity was not statistical different between the unruptured aneurysm and ruptured aneurysm $(2.2 \%$ vs. $4.1 \%)$. The results was similar to the meta-analysis, which showed that morbidity was lower in unruptured very small aneurysms compared to ruptured aneurysm (2.5\% vs. $4.0 \%$ ) [4].

The ruptured very small wide-necked intracranial aneurysm is indicated to management undoubtedly, the way of intervention (surgical repairing or coiling) should be assessing by the institutional outcome and the patient's condition. However, the treatment of unruptured very small wide-necked intracranial aneurysms has to consider the low risk of spontaneous rupture of such lesions and the risks of intervention. As for unruptured very small wide-necked aneurysm, more factors must be considered. The key factor included: patient age, life expectancy, and comorbid disease; previous subarachnoid hemorrhage, family history of subarachnoid hemorrhage, or nicotine use; aneurysm size, location and lobulation; growth or de novo aneurysm formation on serial imaging; risk of treatment [27]. Those having history of subarachnoid hemorrhage, family history of subarachnoid hemorrhage, growth, multiplicity, irregular shape or with a bleb should be considered to treat. In other cases, a good option is probably to have regular imaging (DSA, CTA or MRA) follow-up to detect any modification in size or shape of the aneurysm. Which will lead to an active intervention of these aneurysms [5-7,18,27].

\subsection{Strengthen and limitations}

Our study has several limitations. First, the study is a retrospective research, and the number of patients in this series is small. Second, the study has selection and follow-up bias. The patients with very small unruptured intracranial aneurysms were treated in selected patients, and the percentage of angiographic follow-up for the treated patients is relatively low. Angiographic follow-up was not available due to the wide geographic distribution of our patients in China, their financial limitations, and low compliance. Third, the accuracy of measuring the size of small aneurysms has been limited and, although 3D reconstructed angiography may precisely determine the aneurysm size and volume, the subjectively defined grayscale thresholding can produce large variations in the partial size and volume calculation. Fourth, due to a lack of long-term follow-up of coiling of very small wide-necked intracranial aneurysms, we could not derive conclusions about the long-term efficacy and safety of coiling of these lesions.

\section{Conclusions}

The rate of complication, anatomical results and clinical outcomes of stent-assisted coiling for very small wide-necked 
intracranial aneurysm was low and favorable. However, based on low risk of spontaneous rupture of such aneurysms, the coiling of unruptured such aneurysms must be cautious and in selected patients, its long-term efficacy and safety should be further evaluated in larger prospective series.

\section{Conflict of interest}

None declared.

\section{Acknowledgment and financial support}

This article was supported by the National Natural Science Foundation (No. 81441038 and No. 81371314), the Natural Science Foundation of Beijing, China (No. 7142032), the Specific Research Projects for Capital Health Development (No. 2014-32044 and No. 2011-1015-04).

\section{Ethics}

The work described in this article has been carried out in accordance with The Code of Ethics of the World Medical Association (Declaration of Helsinki) for experiments involving humans; Uniform Requirements for manuscripts submitted to Biomedical journals.

\section{REFERENCES}

[1] Molyneux A, Kerr R, International Subarachnoid Aneurysm Trial Collaborative Group, Stratton I, Sandercock P, Clarke M, et al. International subarachnoid aneurysm trial (ISAT) of neurosurgical clipping versus endovascular coiling in 2143 patients with ruptured intracranial aneurysms: a randomized trial. J Stroke Cerebrovasc Dis 2002;11:304-14.

[2] Cognard C, Weill A, Castaings L, Rey A, Moret J. Intracranial berry aneurysms: angiographic and clinical results after endovascular treatment. Radiology 1998;206:499-510.

[3] Doerfler A, Wanke I, Egelhof T, Dietrich U, Asgari S, Stolke $\mathrm{D}$, et al. Aneurysmal rupture during embolization with guglielmi detachable coils: causes, management, and outcome. AJNR Am J Neuroradiol 2001;22:1825-32.

[4] Brinjikji W, Lanzino G, Cloft HJ, Rabinstein A, Kallmes DF. Endovascular treatment of very small ( $3 \mathrm{~mm}$ or smaller) intracranial aneurysms: report of a consecutive series and a meta-analysis. Stroke 2010;41:116-21.

[5] International Study of Unruptured Intracranial Aneurysms Investigators. Unruptured intracranial aneurysms - risk of rupture and risks of surgical intervention. N Engl J Med 1998;339:1725-33

[6] Wiebers DO, Whisnant JP, Huston 3rd J, Meissner I, Brown Jr RD, Piepgras DG, et al. Unruptured intracranial aneurysms: natural history, clinical outcome, and risks of surgical and endovascular treatment. Lancet 2003;362:103-10.

[7] Investigators UJ, Morita A, Kirino T, Hashi K, Aoki N, Fukuhara S, et al. The natural course of unruptured cerebral aneurysms in a Japanese cohort. N Engl J Med 2012;366:2474-82.
[8] Raymond J, Roy D, Bojanowski M, Moumdjian R, L'Esperance G. Endovascular treatment of acutely ruptured and unruptured aneurysms of the basilar bifurcation. J Neurosurg 1997;86:211-9.

[9] Goddard JK, Moran CJ, Cross 3rd DT, Derdeyn CP. Absent relationship between the coil-embolization ratio in small aneurysms treated with a single detachable coil and outcomes. AJNR Am J Neuroradiol 2005;26:1916-20.

[10] Tsutsumi M, Aikawa H, Onizuka M, Kodama T, Nii K, Matsubara S, et al. Endovascular treatment of tiny ruptured anterior communicating artery aneurysms. Neuroradiology 2008;50:509-15.

[11] Hong B, Yang PF, Zhao R, Huang QH, Xu Y, Yang ZG, et al. Endovascular treatment of ruptured tiny intracranial aneurysms. J Clin Neurosci: Off J Neurosurg Soc Austral 2011;18:655-60.

[12] Weber W, Bendszus M, Kis B, Boulanger T, Solymosi L, Kuhne D. A new self-expanding nitinol stent (Enterprise) for the treatment of wide-necked intracranial aneurysms: initial clinical and angiographic results in 31 aneurysms. Neuroradiology 2007;49:555-61.

[13] Gupta V, Chugh M, Jha AN, Walia BS, Vaishya S. Coil embolization of very small ( $2 \mathrm{~mm}$ or smaller) berry aneurysms: feasibility and technical issues. AJNR Am J Neuroradiol 2009;30:308-14.

[14] Kwon HJ, Park JB, Kwon Y, Ahn JS, Kwun BD. Long-term clinical and radiologic results of small cerebral aneurysms embolized with 1 or 2 detachable coils. Surg Neurol 2006;66:507-12.

[15] Lu J, Liu JC, Wang LJ, Qi P, Wang DM. Tiny intracranial aneurysms: endovascular treatment by coil embolisation or sole stent deployment. Eur J Radiol 2012;81:1276-81.

[16] Molyneux AJ, Kerr RS, Birks J, Ramzi N, Yarnold J, Sneade M, et al. Risk of recurrent subarachnoid haemorrhage, death, or dependence and standardised mortality ratios after clipping or coiling of an intracranial aneurysm in the international subarachnoid aneurysm trial (ISAT): long-term follow-up. Lancet Neurol 2009;8:427-33.

[17] Nguyen TN, Raymond J, Guilbert F, Roy D, Berube MD, Mahmoud M, et al. Association of endovascular therapy of very small ruptured aneurysms with higher rates of procedure-related rupture. J Neurosurg 2008;108:1088-92.

[18] Pierot L, Barbe C, Spelle L, A. Investigators. Endovascular treatment of very small unruptured aneurysms: rate of procedural complications, clinical outcome, and anatomical results. Stroke 2010;41:2855-9.

[19] Ioannidis I, Lalloo S, Corkill R, Kuker W, Byrne JV. Endovascular treatment of very small intracranial aneurysms. J Neurosurg 2010;112:551-6.

[20] Wanke I, Forsting M. Stents for intracranial wide-necked aneurysms: more than mechanical protection. Neuroradiology 2008;50:991-8.

[21] Lopes D, Sani S. Histological postmortem study of an internal carotid artery aneurysm treated with the neuroform stent. Neurosurgery 2005;56:E416. discussion E416.

[22] van Rooij WJ, Keeren GJ, Peluso JP, Sluzewski M. Clinical and angiographic results of coiling of 196 very small $(<$ or $=3 \mathrm{~mm}$ ) intracranial aneurysms. AJNR Am J Neuroradiol 2009;30:835-9.

[23] Yang MS, Wong HF, Yang TH, Chen YL, Chan SW, Lee HJ, et al. Alternative option in the treatment of very small ruptured intracranial aneurysms. Surg Neurol 2009;72 (Suppl. 2):S41-6.

[24] Chalouhi N, Dumont AS, Hasan D, Tjoumakaris S, Gonzalez LF, Starke RM, et al. Is packing density important 
in stent-assisted coiling? Neurosurgery 2012;71:381-6. discussion 386-7..

[25] Sonobe M, Yamazaki T, Yonekura M, Kikuchi H. Small unruptured intracranial aneurysm verification study: Suave study, Japan. Stroke 2010;41:1969-77.

[26] Morita A. Current perspectives on the unruptured cerebral aneurysms: origin, natural course, and management.
J Nippon Med School Nippon Ika Daigaku Zasshi 2014;81:194.

[27] Brown Jr RD, Broderick JP. Unruptured intracranial aneurysms: epidemiology, natural history, management options, and familial screening. Lancet Neurol 2014;13:393-404. 